\title{
PLANEJAMENTO DO TRAÇADO DE UMA TRILHA INTERPRETATIVA ATRAVÉS DA CARACTERIZAÇÃO FLORÍSTICA
}

Joema Carvalho' Roberto Bóçon ${ }^{2}$

\begin{abstract}
RESUMO
O presente trabalho foi realizado em uma área sob a concessão do Hotel Tropical Cataratas - Eco Resort, o qual encontra-se localizado na zona de uso intensivo no Parque Nacional do Iguaçu, Foz do Iguaçu - PR.. Este teve como objetivo o planejamento do traçado de uma trilha interpretativa através da caracterização florística. Para isto, foram utilizadas 15 parcelas de $10 \mathrm{mx} 10 \mathrm{~m}$, nas quais foram medidas todas as espécies arbóreas com diâmetro superior a $5 \mathrm{~cm}$. A definição do traçado da trilha foi através de critérios subjetivos, utilizando-se de indicadores que receberam pontuações para Status, Beleza Cênica e Utilização Antrópica. Os resultados indicam que a área de estudos trata-se de um remanescente de Floresta Estacional Semidecidual Submontana, que sofreu exploração seletiva em períodos anteriores. Os indivíduos com maior pontuação indicaram o traçado da trilha e as parcelas que apresentaram as maiores pontuações oferecerão oportunidades para a elaboração de painéis interpretativos, bem como para a interpretação guiada.

Palavras Chaves: trilha, planejamento, vegetação
\end{abstract}

\section{FLORISTIC CARACTERIZATION AS A TOOL FOR INTERPRETATIVE TRAIL PLANNING}

\begin{abstract}
The information were gathered in the concession area of the Hotel Tropical das Cataratas Eco Resort, Intensive Use Zone of the National Iguaçu Park (Foz do Iguaçu, PR.). The aim of this work was the characterize the vegetation at the study site in order to plan the trace of an interpretative trail. The floristic characterization was done through 15 parcels $(10 \mathrm{mx} 10 \mathrm{~m}$ each), where was measured all trees over $5 \mathrm{~cm}$ of diameter of breast height. Trail definition was done based on pointed criteria as Status Scenic Beauty and Anthropic Utilization. According to the results, the forest analysed is a remnant of the pristine forest. Species with high points along the parcels, defined the track. Parcels scored with highpoint numbers of the chosen criteria suggested the opportunity for implementation of guided tours and illustrative signs along the interpretative trail.
\end{abstract}

Key Words: trail, planning, vegetation.

\section{INTRODUÇ̃̃O}

Ao longo dos tempos, a humanidade vem utilizando-se de caminhos para o deslocamento com fins de suprir suas necessidades básicas como busca de alimentos, reconhecimento e conquista de novos territórios. Através dos processos evolutivos sócio-culturais, as trilhas foram sendo utilizadas para outras finalidades como viagens comerciais e peregrinações religiosas (Andrade e Rocha, 1992; Dias e Queiroz, 1997; Vasconcelos, 1998). Com o advento da revolução industrial e mais recentemente com as evoluções tecnológicas, que propiciaram facilidades de deslocamentos aliadas à influência dos meios de comunicação e principalmente o desejo de conhecer novos lugares, as trilhas passaram a ser utilizadas para o desenvolvimento de atividades de lazer e turismo, longe dos grandes centros urbanos (Takahashi, 1997; Barros, 1997).

Belart (1978), cita que "andar, caminhar, excursionar, longe do agito e da perturbação das grandes cidades consiste em um dos passatempos favoritos da maioria das pessoas". A visitação em um ambiente natural é realizada por meio de caminhos pela floresta, ou trilhas previamente delimitadas, que são implementados e mantidos de acordo com o objetivo e característica de cada sítio. Um dos principais meios utilizados, tanto para a prática

${ }^{1}$ joemacvl@pop.com.br, eng. Florestal Msc, pesquisadora do Mater Natura - Instituto de Estudos Ambientais. Rua Francisco Knopik, 670, 80706-550, Araucária, PR.

${ }^{2}$ rbocob@pop.com.br, biólogo Msc., pesquisador da Sociedade de Pesquisa em Vida Selvagem e Educação Ambiental - SPVS. Rua Francisco Knopik, 670, 80706-550, Araucária, PR.

Recebido para publicação: 27/06/2003

Aceito para publicação: 25/11/2003 
de recreação como para a conscientização ambiental, tem sido as "trilhas interpretativas" ou "trilhas de interpretação" (Vasconcelos, 1998, Takahashi, 1997). A busca de sítios protegidos como prática de recreação levou à implementação de trilhas e caminhos para serem utilizados como um instrumento de informação, sensibilização e conscientização.

As trilhas interpretativas se bem planejadas, constituem-se de importante instrumento pedagógico, o qual, propicia o contato mais próximo entre o homem e a natureza. Cada vez mais são utilizadas em programas de Educação Ambiental, uma vez que, através do processo de sensibilização, fomenta a aquisição de conhecimentos cognitivos relativos ao meio ambiente, fundamentais para a formação de valores e mudanças de comportamento (Guillaumon et al., 1997; Vasconcelos, 1998). A prática de caminhar em ambientes naturais possibilita uma melhor compreensão do meio ambiente e suas inter-relações, aguçando ainda, uma dinâmica de observação, de reflexão e de sensibilização para com as questões relativas ao meio ambiente. Sua necessidade tem-se mostrado como de grande importância diante dos valores econômicos e sociais que têm distanciado o ser humano da realidade e do seu contato com o meio ambiente (Guillaumon et al., 1977).

O levantamento de informações relativas ao meio biofísico, a avaliação de impactos e o planejamento prévio são fundamentais na implantação de trilhas interpretativas (Echelberger et al., 1978); Chaverri e Cristopher, 1981; Agate, 1993). A implantação de trilhas interpretativas deve considerar, dentre outros fatores, o potencial da área no que diz respeito aos aspectos naturais, como a importância ecológica e a beleza cênica (Padua 1997; Ham, 1992; Vasconcelos, 1998).

Como componente do Sistema de Gerenciamento Ambiental do Hotel Tropical das Cataratas Eco Resort, localizado em zona de uso intensivo do Parque Nacional do Iguaçu, o programa de educação e sensibilização ambiental apontou a necessidade da implantação de uma trilha interpretativa. Com a finalidade de suprir esta carência, o presente trabalho teve como objetivo o planejamento do traçado de uma trilha interpretativa com base em um estudo fitossociológico e indicadores definidos por meio de critérios subjetivos.

\section{MATERIAL E MÉTODOS}

\section{Caracterização da área de estudo}

O presente trabalho foi desenvolvido na área do Hotel Tropical das Cataratas Eco Resort inserido em uma zona de uso intensivo no Parque Nacional do Iguaçu (PNI), município de Foz do Iguaçu no Estado do Paraná (IBAMA, 1999). A região geográfica do PNI é caracterizada por possuir um clima subtropical úmido ou mesotérmico (Cfa) com verão pronunciado e com a possibilidade de uma pequena seca durante o inverno (Köeppen e De Long, 1958). As temperaturas médias estão entre $15^{\circ} \mathrm{C}$ (inverno) e $25^{\circ} \mathrm{C}$ (verão) (IBAMA, 1999). O regime de chuvas reflete o comportamento de clima de transição, apresentando índices pluviométricos elevados, entre $1.500 \mathrm{~mm}$ a $2.000 \mathrm{~mm}$ anuais.

$\mathrm{Na}$ área de estudo são encontradas duas classes de solo: Nitossolo Vermelho Eutroférrico Latossólico, A Moderado, textura argilosa, fase floresta tropical perenifólia, relevo suave ondulado NV ef4; e Gleissolos indiscriminados fase floresta tropical perenifólia de várzea relevo plano GMX1 (EMBRAPA 1981 e 1999).

Considerando a caracterização realizada por Ziller (1998), no Parque Nacional do Iguaçu ocorrem quatro diferentes formações vegetais, distribuídas de maneira heterogênea, em função de diferenças altitudinais e variações no meio físico: Floresta Estacional Semidecidual Montana, Submontana e Aluvial e Floresta Ombrófila Mista.

\section{Caracterização florística}

Para a caracterização da vegetação na área de estudo foram demarcadas 15 parcelas com dimensões de $10 \mathrm{mx} 10 \mathrm{~m}$, dispostas ao longo do traçado prévio da trilha interpretativa. Dentro das parcelas foram levantadas todas as espécies arbóreas com diâmetro a altura do peito (DAP) acima de $5 \mathrm{~cm}$.

As medidas dos diâmetros foram obtidas utilizando-se uma fita métrica, as alturas foram estimadas e os dados obtidos foram anotados em fichas de campo.

As espécies foram identificadas in loco através de observações de suas estruturas, 
inflorescências e frutos, e comparadas com bibliografia especializada (Lorenzi 1998 e 2000). Espécies não identificadas tiveram suas estruturas foliares coletadas e posteriormente comparadas em herbários.

Os parâmetros fitossociológicos abordados no presente trabalho foram densidade, freqüência e dominância absolutas e relativas, valor de importância e índice de diversidade de Shannon, calculados através de uma planilha do Excel 1998.

\section{Indicadores da trilha interpretativa}

Com base nos resultados do levantamento fitossociológico realizado na área de estudo, foram definidos indicadores que receberam pontuações distintas. Os indicadores selecionados foram diferenciados devido a respectiva relevância na aplicação de uma trilha interpretativa, atribuídas, conforme abaixo:

O indicador Status (S) com pontuação (1) refere-se às espécies vegetais arbóreas ameaçadas, conforme a lista oficial de espécies ameaçadas do estado do Paraná (1995) e do Instituto Brasileiro de Meio Ambiente e dos Recursos Naturais Renováveis - IBAMA.

Beleza Cênica (BC) com pontuação (3), foi o indicador que considerou todas as espécies arbóreas com diâmetro a altura do peito (DAP) superior ou igual a $30 \mathrm{~cm}$ e com características estruturais individuais relevantes, como o formato de copa e a estrutura do tronco.

O indicador Utilização Antrópica (UA), com pontuação (2), considerou todas as espécies endêmicas e com potencial de aproveitamento humano. Para a definição deste critério foram utilizadas duas referências bibliográficas Reitz et al. (1978) e Lorenzi (1998, 2000).

Com base nestes indicadores, os indivíduos arbóreos amostrados dentro das parcelas foram selecionados e pontuados. Os indivíduos com as maiores pontuações sugeriram o traçado final da trilha interpretativa.

\section{RESULTADOS E DISCUSSÃO}

\section{Caracterização florística}

Os resultados apontaram um total de 241 indivíduos, distribuídos em 15 famílias, 23 gêneros e 29 espécies vasculares. Nove espécies (31\%) não foram identificadas ao nível específico (tabela 1).
A família com maior representatividade foi Meliaceae, com 4 gêneros e 5 espécies (Cabralea canjerana, Cedrela fissilis, Guarea kunthiana, Trichillia catigua e Trichillia elegans), totalizando $17 \%$ das espécies levantadas (tabela 1).

O Índice de Shannon encontrado foi 3,698. Silva (1990), estudando o Parque Estadual Mata dos Godoy, no norte do Estado do Paraná, encontrou o mesmo índice $\mathrm{H}^{\prime}=3,69$. Segundo esta autora, este índice é superior ao registrado em algumas formações de Floresta Estacional Semidecidual do planalto paulista, sendo que a maior semelhança, em relação a diversidade, ocorreu com a Mata de Capetinga.

Guarea kunthiana foi à espécie que apresentou o maior valor de importância $(52,58 \%)$, o que refletiu os seus altos valores de densidade $(27,39 \%)$, freqüência $(11,97 \%)$ e dominância $(13,22 \%)$. A segunda espécie em valor de importância foi Sorocea bonplandii $(35,91 \%)$, devido os seus altos valores de densidade $(20,75 \%)$ e freqüência $(11,97 \%)$ (tabela 2).

Balfourodendron riedelianum também obteve um alto valor de importância $(23,27 \%)$, como conseqüência de sua densidade $(8,71 \%)$, freqüência $(8,55 \%)$ e dominância $(6,01 \%)$. Da mesma forma, Bastardinopsis densiflora possuiu um valor de importância $(20,09 \%)$, devido aos valores de densidade (4,56\%), freqüência $(5,98 \%)$ e dominância $(9,54 \%)$ (tabela 2).

As espécies Patagonula americana (15,02\%), Nectandra megapotamica (9,03\%), Holocalix balansae $(11,16 \%)$ obtiveram altos valores de dominância, o que refletiu em valores significativos de valor de importância (tabela 2). Balfourodendron riedelianum, Bastardinopsis densiflora, Patagonula americana, Holocalix balansae são espécies endêmicas da Floresta Estacional Semidecidual, caracterizando esta tipologia. Possuem alta longevidade e são típicas no estádio intermediário de sucessão, permanecendo até um estádio mais maduro de desenvolvimento da comunidade florestal (Inoue et. al., 1984; Reitz et al., 1978). Apesar de Guarea kunthiana, Sorocea bonplandii e Nectandra megapotamica não serem endêmicas, a abundância destas espécies nos estratos inferiores é típica da Floresta Estacional Semidecidual em estádios médio e avançado. 
Tabela 1: Espécies arbóreas amostradas ao longo do traçado preliminar da trilha interpretativa, Foz do Iguaçu, PR Table 1: $\quad$ Arboreal species sampled into the floristic characterization of the interpretative traill, Foz do Iguacu, PR

\begin{tabular}{|c|c|c|}
\hline FAMÍLIA & ESPÉCIE & NOME POPULAR \\
\hline BORAGINACEAE & Patagonula americana $\mathrm{L}$. & Guajuvira \\
\hline CAESALPINIACEAE & Holocalyx balansae Mich. & Alecrim \\
\hline CARICACEAE & Jacaratia spinosa (Aubl.) A.DC. & Jaracatiá \\
\hline EUPHORBIACEAE & Alchornea triplinervia (Spreng.) M. ARG. & Tapiá \\
\hline \multirow[t]{2}{*}{ LAURACEAE } & Nectandra megapotamica (Spreng.) Mez. & Canela-preta \\
\hline & Nectandra lanceolata Nees et Mart. ex Nees & Caneal-amarela \\
\hline MALVACEAE & Bastardiopsis densiflora (Hook et Arn) Hass. & Jangada \\
\hline \multirow[t]{5}{*}{ MELIACEA } & Cabralea canjerana (Vell.) Mart. & Canjerana \\
\hline & Guarea kunthiana A. Juss. & Catiguá-de-morcego \\
\hline & Cedrela fissilis Vell. & Cedro \\
\hline & Trichillia catigua A Juss. & Catiguá \\
\hline & Trichillia elegans A. Juss. & Catiguá \\
\hline MIMOSACEAE & Parapiptadenia rigida (Benth.) Brenan & Anjico-vermelho \\
\hline \multirow[t]{2}{*}{ MORACEAE } & Ficus sp. & Figueira \\
\hline & Sorocea bonplandii (Baill.) Burger, Lanjow \& Boer & Cancorosa \\
\hline MYRSINACEAE & Myrsine sp. & Capororoca \\
\hline MYRTACEAE & $\begin{array}{l}\text { Campomanesia xanthocarpa O. Berg. } \\
\text { Eugenia } \mathrm{sp} \\
\text { Espécie Indeterminada } 1\end{array}$ & Guabiroba \\
\hline ROSACEAE & Prunus sellowii Koehne & Pessegueiro-do-mato \\
\hline \multirow[t]{4}{*}{ RUTACEAE } & Balfourodendron riedelianum (Engl.) Engl. & Pau-marfim \\
\hline & Citrus sp. & Laranjeira \\
\hline & Pilocarpus pennatifolius Lem & Jaborandi \\
\hline & Zanthoxyllum sp. & Mamica-de-cadela \\
\hline SAPINDACEAE & Diatenopteryx sorbifolia Radlk. & Maria-preta \\
\hline SAPOTACEAE & $\begin{array}{l}\text { Crysophyllum marginatum (Hook. \& Arn) Radlk. } \\
\text { Espécie Indeterminada } 2 \\
\text { Espécie Indeterminada } 3 \\
\text { Espécie Indeterminada } 4\end{array}$ & Aguaí \\
\hline
\end{tabular}

O diâmetro a altura do peito (DAP) médio dos troncos dos indivíduos amostrados foi de $17,6 \mathrm{~cm}$, variando de $5 \mathrm{~cm}$ até $151,27 \mathrm{~cm}$, representado por um indivíduo da espécie Patagonula americana. A altura média do componente amostrado foi de $17 \mathrm{~m}$, variando de 4,5m (Guarea kunthiana) a $30 \mathrm{~m}$ (Patagonula americana e Balfourodendron riedelianum). Ziller e Hatchbach (s/d) caracterizando APA de Ilha Grande e Ziller (1998), caracterizando uma fase avançada da Floresta Estacional Semidecidual do Parque Nacional do Iguaçu, constataram que o estrato emergente era dominado por espécies com diâmetros próximos de $1 \mathrm{~m}$ e alturas de $35 \mathrm{~m}$, o qual, era rico em espécies de alto valor madeireiro. Ziller e Hatchbach (s/d) acrescentam, que a divisão desse estrato e o imediatamente abaixo ocorre entre $18 \mathrm{~m}$ e $25 \mathrm{~m}$, com árvores de DAP em torno de $60 \mathrm{~cm} \mathrm{e}$ eventuais mais grossas, indicando a ausência de exemplares de grande porte, que possivelmente sofreram exploração no passado.

Maack (1968), estudando uma Floresta Estacional Semidecidua, cita que no extrato superior destacam-se Aspidosperma polyneuron, Cedrela fissilis, Holocalyx balansae, Balfourodendron riedelianum, Peltophorum dubium, Parapiptadenia rigida, Apuleia leiocarpa, Enterolobium contortisiliquum, Patagonula americana, Cordia trichotoma. Também, Syagrus romanzoffianum, Casearia sylvestris, Strychnos brasiliensis, Nectandra lanceolata, Cabralea canjerana, Luehea divaricata. Segundo Leite e Klein (1990), no estrato emergente também pode se verificar Tabebuia avellanedae e Gallesia gorazema e no estrato contínuo de maneira bastante freqüente Nectandra megapotamica e Euterpe edulis. 
Tabela 2: Estimativa dos parâmetros fitossociológicos das espécies arbóreas amostradas ao longo do traçado preliminar da trilha interpretativa, Foz do Iguaçu, PR

Table 2: Estimative of the phytosociologycal parameters of the arboreal species sampled into the interpretative traill, Foz do Iguaçu, PR

\begin{tabular}{|c|c|c|c|c|c|c|c|}
\hline \multirow[t]{2}{*}{ Nomes científicos } & \multicolumn{2}{|c|}{ Densidade } & \multicolumn{2}{|c|}{ Dominância } & \multicolumn{2}{|c|}{ Freqüência } & \multirow[t]{2}{*}{ VI } \\
\hline & $\begin{array}{c}\text { Abs } \\
\left(\mathrm{n} \cdot \mathrm{ha}^{-1}\right)\end{array}$ & $\begin{array}{l}\text { Rel } \\
(\%)\end{array}$ & $\begin{array}{c}\text { Abs } \\
\left(\mathrm{m}^{2} \cdot \mathrm{ha}^{-}\right. \\
1)\end{array}$ & $\begin{array}{l}\text { Rel } \\
(\%)\end{array}$ & $\begin{array}{l}\text { Abs. } \\
(\%)\end{array}$ & $\begin{array}{l}\text { Rel. } \\
(\%)\end{array}$ & \\
\hline Guarea kunthiana & 440 & 27,39 & 10,58 & 13,22 & 93,33 & 11,97 & 52,58 \\
\hline Sorocea bonplandii & 333 & 20,75 & 2,55 & 3,19 & 93,33 & 11,97 & 35,91 \\
\hline Balfourodendron riedelianum & 140 & 8,71 & 4,81 & 6,01 & 66,67 & 8,55 & 23,27 \\
\hline Bastardiopsis densiflora & 73 & 4,56 & 7,63 & 9,54 & 46,67 & 5,98 & 20,09 \\
\hline Patagonula americana & 20 & 1,24 & 12,02 & 15,02 & 20,00 & 2,56 & 18,83 \\
\hline Nectandra megapotamica & 53 & 3,32 & 7,23 & 9,03 & 40,00 & 5,13 & 17,48 \\
\hline Holocalix balansae & 33 & 2,07 & 8,93 & 11,16 & 26,67 & 3,42 & 16,65 \\
\hline Jacaratia spinosa & 33 & 2,07 & 3,87 & 4,84 & 33,33 & 4,27 & 11,19 \\
\hline Cabralea canjerana & 53 & 3,32 & 2,58 & 3,23 & 33,33 & 4,27 & 10,82 \\
\hline Ficus sp. & 20 & 1,24 & 5,47 & 6,83 & 20,00 & 2,56 & 10,64 \\
\hline Parapiptadenia rigida & 33 & 2,07 & 3,70 & 4,63 & 26,67 & 3,42 & 10,12 \\
\hline Espécie Inderteminada 1 & 67 & 4,15 & 0,31 & 0,39 & 40,00 & 5,13 & 9,67 \\
\hline Pilocarpus pennatifolius & 33 & 2,07 & 1,28 & 1,60 & 26,67 & 3,42 & 7,09 \\
\hline Trichillia catigua & 47 & 2,9 & 0,20 & 0,25 & 26,67 & 3,42 & 6,58 \\
\hline Campomanesia xanthocarpa & 27 & 1,66 & 0,27 & 0,34 & 26,67 & 3,42 & 5,42 \\
\hline Trichillia elegans & 33 & 2,07 & 0,28 & 0,35 & 20,00 & 2,56 & 4,99 \\
\hline Diatenopterix sorbifolia & 13 & 0,83 & 1,84 & 2,30 & 13,33 & 1,71 & 4,84 \\
\hline Alchornea triplinervia & 7 & 0,41 & 2,76 & 3,45 & 6,67 & 0,85 & 4,72 \\
\hline Rapanea sp. & 20 & 1,24 & 0,60 & 0,75 & 20,00 & 2,56 & 4,55 \\
\hline Eugenia sp. & 27 & 1,66 & 0,20 & 0,25 & 20,00 & 2,56 & 4,48 \\
\hline Prunus brasiliensis & 20 & 1,24 & 1,00 & 1,25 & 13,33 & 1,71 & 4,20 \\
\hline Nectandra lanceolata & 13 & 0,83 & 0,52 & 0,65 & 13,33 & 1,71 & 3,19 \\
\hline Zanthoxyllum sp. & 13 & 0,83 & 0,06 & 0,07 & 13,33 & 1,71 & 2,61 \\
\hline Espécie Inderteminada 2 & 13 & 0,83 & 0,55 & 0,69 & 6,67 & 0,85 & 2,38 \\
\hline Espécie Inderteminada 3 & 7 & 0,41 & 0,62 & 0,77 & 6,67 & 0,85 & 2,04 \\
\hline Citrus sp. & 13 & 0,83 & 0,06 & 0,08 & 6,67 & 0,85 & 1,76 \\
\hline Cedrela fissilis & 7 & 0,41 & 0,03 & 0,03 & 6,67 & 0,85 & 1,30 \\
\hline Crysophyllum marginata & 7 & 0,41 & 0,02 & 0,02 & 6,67 & 0,85 & 1,29 \\
\hline Espécie Inderteminada 4 & 7 & 0,41 & 0,02 & 0,02 & 6,67 & 0,85 & 1,29 \\
\hline Total & 1607 & 100 & 79,99 & 100 & 780 & 100 & 300 \\
\hline
\end{tabular}

Ziller (1998), caracterizando a mesma tipologia em sua fase avançada de sucessão no Parque Nacional do Iguaçu, acrescenta as espécies: Myrocarpus frondosus, Lonchocarpus muehlenbergianus e Rollinia salicifolia, acompanhadas por Chorisia speciosa,
Chrysophyllum gonocarpum, Roupala brasiliensis, Ficus insipida, Campomanesia xanthocarpa, Matayba elaeagnoides, Cupania vernalis, Anadenanthera colubrina, Diatenopteryx sorbifolium, Prunus sellowii e Pilocarpus pennatifolius. No estrato mais baixo 
cita como típicas Sorocea bonplandii, Euterpe edulis, Allophylus edulis, Guarea kunthiana, Endlicheria paniculata, Eugenia uniflora e Sapium glandulatum.

Ziller e Hatchbach (s/d) acrescentam Aspidosperma cylindrocarpon, Astronium graveolens, Jacaratia spinosa e Pterogyne nitens. No sub-bosque, Ocotea acutifolia, Colunbrina glandulosa, Helietta longifoliata e Acromia aculeata, Copaifera langsdorffii, Esenbeckia febrifuga, Margaritaria nobilis, Casearia obliqua, Casearia gossypiosperma, Banara tomentosa, Sebastiania commersoniana, Tabebuia crysotrycha, Machaerium nytitans, Inga marginata, Trichillia catigua, Trichillia pallida, Cordia ecalyculata, Eugenia hiemalis, Eugenia florida, Heliocarpus americanus e Aloysia pulchra.

No levantamento florístico foram constatadas duas espécies arbóreas ameaçadas de extinção: Jacaratia spinosa, espécie da família Caricaceae e Balfourodendron riedelianum, a mais importante das madeiras brasileiras da família Rutaceae (Inoue et al., 1984; Reitz et al., 1978).

Constatou-se a presença de dois indivíduos de Citrus sp. Na parcela 4, que são exóticos e comumente cultivados em pomares. Também, foram encontradas espécies exóticas ornamentais, utilizadas no paisagismo do hotel, que se propagaram para o interior da floresta. Entre elas destacam-se: Dracena fragans, Impatiens walleriana, Pilea cardierei, Tradescantia zebrina, Hydrocotyloe bonariensis.

\section{Avaliação do traçado da trilha interpretativa}

O indicador "Status" foi verificado em $73 \%$ das parcelas. As espécies Balfourodendron riedelianum e Jacaratia spinosa foram selecionadas por serem ameaçadas de acordo com a Lista Oficial de Espécies Ameaçadas de Extinção do Estado do Paraná.

O indicador "Beleza Cênica" foi constatado em $80 \%$ das parcelas. Merecem destaque às espécies Nectandra lanceolata, Ficus sp. e Patagonula americana devido à exuberância de seu porte e Holocalix balansae, pelo desenho típico do seu tronco.

Com relação ao indicador "Utilização Antrópica", verificou-se que em 93\% das parcelas ocorreram espécies endêmicas com potencial para utilização antrópica. A presença destas espécies oferece a oportunidade para a discussão da importância dos valores econômicos-sociais regionais que de acordo com Guillaumon et. al. (1977), tem distanciado o ser humano da realidade e do seu contato com o meio ambiente.

Os resultados encontrados vêm de encontro com os objetivos propostos para trilhas interpretativas, segundo autores como Ham (1992) e Andrade e Rocha (1992), que afirmam que a implantação de trilhas interpretativas deve considerar dentre outros aspectos a presença de elementos potenciais que despertem a atenção do usuário.

A trilha interpretativa, além do contato direto do freqüentador com o elemento ou fenômeno observado, propicia uma interação entre os vários componentes envolvidos (Ham, 1992). Tilden (1957), cita que a interpretação ambiental não é simplesmente a transmissão de informações, mas uma atividade educacional que revela os significados e características do ambiente através do uso de objetos originais por experiência direta e por meios ilustrativos.

A sugestão para o traçado principal da trilha interpretativa considera os indivíduos que obtiveram a maior pontuação, dentro de cada parcela, em relação aos indicadores (S, BC, UA) (tabela 3). Não necessariamente serão considerados todos os indivíduos com as maiores pontuações, levando-se em conta a repetição das espécies dentro e entre as parcelas, gerando possibilidades de diferentes traçados:

Desta forma, Nectandra lanceolata (parcela 1) é espécie que indica o início da trilha, podendo ser seguida por Diatenopterix sorbifolia (parcela 2), Holocalix balansae (parcela 3), pelos indivíduos da espécie Parapiptadenia rigida (parcela 4), Ficus sp. e Parapiptadenia rigida (parcela 5), Parapiptadenia rigida (parcela 6), pelos indivíduos da espécie Bastardiopsis densiflora e Parapiptadenia rigida (parcela 7), pelos indivíduos da espécie Balfourodendron riedelianum (parcela 8), Jaracatia spinosa (parcela 9), Jaracatia spinosa e Balfourodendron riedelianum (parcela 10), pelos indivíduos da espécie Balfourodendron riedelianum (parcela 11), Pilocarpus pennatifolius (parcela 12), Jaracatia spinosa e Balfourodendron riedelianum (parcela 13), Balfourodendron riedelianum (parcela 14), 
Diatenopterix sorbifolia e Holocalix balansae (parcela 15).

O traçado da trilha é definido com base nas espécies arbóreas, indicando um traçado principal. No entanto, o traçado final da trilha deve ser enriquecido por considerações as demais sinusias da floresta e as diferentes formas vegetais, como epífitas, cipós, arbustivas, herbáceas, as quais não foram avaliadas neste trabalho e que oferecem maior potencial ainda para a trilha. Fato este constatado pela intensa regeneração de Euterpe edulis (parcelas 2, 4, 5, 10, 11 e 15), Bauhinia scandens (cipó-escada) de grande porte (parcelas 3, 9 e 12) e Philodendron sp. (guaimbê) (parcelas 5 e 10).

As parcelas com as maiores pontuações $(4,9,10,11,13)$ oferecem oportunidades para explanação das inter-relações entre os elementos existentes no local, sugerindo a instalação de painéis fixos no caso de implantação de trilha interpretativa auto-guiada. As parcelas 4, 9, 10 e 13 destacaram-se pela presença de espécies com Beleza Cênica. A parcela 11, além de espécies com Beleza Cênica, destacou-se, principalmente, devido ao número de indivíduos com status, dentro dos padrões definidos.

O parâmetro que mais se destacou, foi Beleza Cênica. Foi determinada a maior pontuação para este indicador por atrair mais a atenção do público leigo, evidenciando as diferentes características das espécies, como o porte, o formato de copa, da casca, o suporte para a presença de epífitas, como bromélias, orquídeas e o guaiambé, característico da Floresta Estacional Semidecidual, entre outras.

Tabela 3: Pontuação dos indicadores. Legenda: espécie com status relevante (S); espécies com beleza cênica (BC); espécies com utilidade antrópica (UA), Foz do Iguaçu, PR.

Table 3: Scores for the criteria chosen. Legend: Relevant Status Species (S); scenic beauty (BC), anthropic utilization (AU), Foz do Iguaçu, PR

\begin{tabular}{|c|c|c|c|c|c|}
\hline PARCELA & ESPÉCIE & $S(1)$ & $\mathrm{BC}(3)$ & UA(2) & TOTAL \\
\hline 1 & Nectandra lanceolata & & 3 & & 3 \\
\hline \multirow[b]{2}{*}{2} & Cabralea canjerana & & 3 & & \\
\hline & Diatenopteryx sorbifolia & & 3 & 2 & 8 \\
\hline \multirow{3}{*}{3} & Balfourodendron riedelianum & & 3 & 2 & \\
\hline & Holocalyx balansae & 1 & 3 & 2 & 11 \\
\hline & Parapiptadenia rigida & & 3 & 2 & \\
\hline \multirow{5}{*}{4} & Bastardiopsis densiflora & 1 & & 2 & 15 \\
\hline & Parapiptadenia rigida & 1 & 3 & 2 & 15 \\
\hline & Balfourodendron riedelianum & & & 2 & \\
\hline & Ficus sp. & & 3 & 2 & \\
\hline & Balfourodendron riedelianum & 1 & & $\begin{array}{l}2 \\
2\end{array}$ & \\
\hline \multirow[t]{4}{*}{5} & Parapiptadenia rigida & & & $\begin{array}{l}2 \\
2\end{array}$ & 12 \\
\hline & Pilocarpus pennatifolius & & & 2 & \\
\hline & Pilocarpus pennatifolius & & & & \\
\hline & Parapiptadenia rigida & & 3 & 2 & \\
\hline \multirow[t]{3}{*}{6} & Parapiptadenia rigida & & & 2 & 10 \\
\hline & Cabralea canjerana & & 3 & & \\
\hline & Bastardiopsis densiflora & & & 2 & \\
\hline \multirow{4}{*}{7} & Bastardiopsis densiflora & & & 2 & \\
\hline & Parapiptadenia rigida & & & 2 & 8 \\
\hline & Bastardiopsis densiflora & & & 2 & \\
\hline & Balfourodendron riedelianum & 1 & & 2 & \\
\hline \multirow{5}{*}{8} & Balfourodendron riedelianum & 1 & & 2 & \\
\hline & Balfourodendron riedelianum & 1 & & 2 & 12 \\
\hline & Balfourodendron riedelianum & 1 & & 2 & \\
\hline & Patagonula americana & & & 2 & \\
\hline & Holocalyx balansae & & 3 & 2 & \\
\hline \multirow[t]{5}{*}{9} & Holocalyx balansae & 1 & & 2 & 17 \\
\hline & Pilocarpus pennatifolius & & & 2 & \\
\hline & Jacaratia spinosa & & 3 & 2 & \\
\hline & & & 3 & 2 & \\
\hline & Jacaratia spinosa & 1 & 3 & $\begin{array}{l}2 \\
2\end{array}$ & \\
\hline \multirow{4}{*}{10} & Bastardiopsis densiflora & 1 & & $\begin{array}{l}2 \\
2\end{array}$ & 21 \\
\hline & Balfourodendron riedelianum & 1 & 3 & $\begin{array}{l}2 \\
2\end{array}$ & 21 \\
\hline & Pilocarpus pennatifolius & & & 2 & \\
\hline & Patagonula americana & & & & \\
\hline
\end{tabular}

Continua... 
Continuação...

\begin{tabular}{|c|c|c|c|c|c|}
\hline \multirow{12}{*}{11} & Balfourodendron riedelianum & 1 & \multirow{3}{*}{3} & & 2 \\
\hline & Balfourodendron riedelianum & 1 & & \multirow{2}{*}{\multicolumn{2}{|c|}{2}} \\
\hline & Nectandra magapotamica & & & & \\
\hline & Balfourodendron riedelianum & 1 & & \\
\hline & Bastardiopsis densiflora & & \multirow{2}{*}{3} & & \multirow{3}{*}{37} \\
\hline & Balfourodendron riedelianum & 1 & & 2 & \\
\hline & Balfourodendron riedelianum & 1 & & 2 & \\
\hline & Balfourodendron riedelianum & 1 & & 2 & \\
\hline & Parapiptadenia rigida & & & 2 & \\
\hline & Balfourodendron riedelianum & 1 & \multirow{2}{*}{3} & \multicolumn{2}{|l|}{2} \\
\hline & Balfourodendron riedelianum & 1 & & \multirow{2}{*}{\multicolumn{2}{|c|}{2}} \\
\hline & Nectandra magapotamica & & & & \\
\hline & Pilocarpus pennatifolius & \multirow{4}{*}{1} & 3 & \multicolumn{2}{|c|}{2} \\
\hline \multirow{4}{*}{12} & Bastardiopsis densiflora & & & 2 & 10 \\
\hline & Balfourodendron riedelianum & & & 2 & \\
\hline & Bastardiopsis densiflora & & & 2 & \\
\hline & Holocalyx balansae & 1 & 3 & 2 & \\
\hline \multirow[t]{5}{*}{13} & Balfourodendron riedelianum & 1 & \multirow[t]{2}{*}{3} & 2 & \multirow[t]{5}{*}{22} \\
\hline & Balfourodendron riedelianum & 1 & & 2 & \\
\hline & Jacaratia spinosa & & 3 & 2 & \\
\hline & Bastardiopsis densiflora & & & 2 & \\
\hline & Bastardiopsis densiflora & & & 2 & \\
\hline \multirow{4}{*}{14} & Patagonula americana & \multirow{3}{*}{\multicolumn{2}{|c|}{1}} & 2 & 11 \\
\hline & Bastardiopsis densiflora & & & 2 & \\
\hline & Balfourodendron riedelianum & & & 2 & \\
\hline & Diatenopteryx sorbifolia & \multirow{3}{*}{1} & 3 & 2 & \\
\hline \multirow[t]{2}{*}{15} & Holocalyx balansae & & 3 & 2 & 13 \\
\hline & Balfourodendron riedelianum & & & 2 & \\
\hline & & 31 & 69 & 114 & \\
\hline
\end{tabular}

\section{CONCLUSÃO}

Os resultados obtidos através da análise fitossociológica indicam que área amostrada trata-se de um remanescente de Floresta Estacional Semidecidual Submontana primária que, conforme IBAMA (1999), em períodos anteriores sofreu exploração seletiva de espécies potenciais para madeira, como Aspidosperma polyneuron e Tabebuia avellanedae e de outras espécies não madeiráveis de interesse econômico, como Euterpe edulis.

Guarea kunthiana, Sorocea bonplandii, Balfouroudendron riedelianum e Bastardinopis densiflora possuíram os maiores valores de importância. Patagonula americana, Nectandra megapotamica, Holocalix balansae obtiveram altos valores de dominância, o que refletiu na composição florística da floresta e em valores de importância significativos. Por outro lado, conforme apontam os resultados, são constatadas espécies remanescentes, endêmicas e duas com status de ameaçada de extinção (Balfouroudendron riedelianum e Jacaratia spinosa), o que caracteriza e valoriza este ambiente no que diz respeito à conservação e utilização em programas de
Educação Ambiental. A presença de espécies exóticas utilizadas no paisagismo contrapõe os objetivos das atividades de interpretação da natureza, o que sugere o manejo das mesmas através de sua retirada gradativa, no caso da implantação da trilha interpretativa.

A pontuação final obtida de cada indicador sugere o potencial da área bem como a delimitação do traçado principal de uma trilha interpretativa na área de estudo. As parcelas que apresentaram as maiores pontuações oferecem oportunidades para a exploração do potencial existente no local, através de painéis interpretativos bem como para atividades de interpretação guiada.

\section{AGRADECIMENTOS}

Conselho Nacional de Desenvolvimento Científico e Tecnológico - CNPq; Instituto Brasileiro do Meio Ambiente e dos Recursos Naturais Renováveis - IBAMA; Parque Nacional do Iguaçu; Administração do Hotel Tropical das Cataratas Eco-Resort, e Dr. ${ }^{\text {a }}$ Ghislaine Miranda Bonduelle. 


\section{REFERÊNCIAS}

AGATE, E. Footpaths: a preatical conservation hand-book. Berkshire, Wembley Press. 1993. 192p.

ANDRADE, W. J. \& ROCHA, L. M. da. Planejamento, implantação e manutenção de trilhas. São Paulo: Instituto Florestal. Brasil. 1992.

BARROS, S. M. Turismo e Unidades de Conservação no Brasil. I Congresso Brasileiro de Unidades de Conservação. Anais. 1997. 298-319p.

BELART, J. L. Trilhas para o Brasil. Bol. FBCN, 13(1): 49-51. 1978

CHAVERRI, A. P.; CHRISTOPHER, W.D. La elaboracion de Senderos naturales como instrumento eductivo. Costa Rica. Facultad de Ciências de la Tierra y El Mar y Ecuela de Ciências Ambientales. Série de Ordenación de Áreas Silvestres, 4 1981. 15p.

DIAS, A. C.;QUEIROZ, M. H. Elaboração de trilha Interpretativa na Unidade de Conservação Desterro. In: Congresso Brasileiro de Unidades de Conservação 2v. Anais. Curitiba. 1997. p.380-388.

ECHELBERGER, H. E.; LEONARD, R. E.; HALBLIN, L. M. The Trail Guild System as a Back Bountry Management Tool. Broonall, Northeastern Forest Esperiment Station. USDA. Rechearch Note ne, 266. 1978. 5p.

EMBRAPA. Levantamento de Reconhecimento de Solos do Estado do Paraná. Curitiba. Mapa 1:600.000. 1981.

EMBRAPA. Centro Nacional de Pesquisa de Solos, Rio de Janeiro. Sistema Brasileiro de Classificação de Solos. Brasília: Embrapa Produção de Informação; Embrapa Solos, 1999. 412p.

GUILLAUMON, J. R: POLL e SINGY, J. M. Análise das trilhas de interpretação. Instituto Florestal de São Paulo .Bol. Técnico n ${ }^{\circ} 25$. São Paulo-SP. 1977. 57p

HAM, S. H. Interpretacion Ambiental: Uma Guia Practica para Gente com Grandes Ideas y Presupuestos Pequenos. North. Am. Press; Colorado USA. 1992. 473p.
HATSCHBACH, G. G. e ZILLER, S. R. Lista vermelha de espécies ameaçadas de extinção no Estado do Paraná. Curitiba: SEMA/GTZ. 1995. 139p.

IBAMA. Plano de Manejo do Parque Nacional do Iguaçu. CD-ROOM. 1999.

IBGE - FUNDAÇÃO INSTITUTO BRASILEIRO DE GEOGRAFIA E ESTATÍSTICA. Manual técnico da vegetação brasileira. Rio de Janeiro:FIBGE, 1992. (Manuais Técnicosde Geociências, $n^{\circ} 1$ ).

INOUE, M. T.; RODERJAN, C. V.; KUNIYOSHI, Y. S. Projeto Madeira do Paraná. Curitiba, Fundação de Pesquisas Florestais do Paraná. 1984.260p.

KOEPPEN, C. E. \& de LONG, G. C. Wheather and Climate. McGraw-Hill. New York. 1958.

LEITE, P. F.; KLEIN, R. M. Vegetação. In: Geografia do Brasil - Região Sul. INSTITUTO BRASILEIRO DE GEOGRAFIA E ESTATÍSTICA - IBGE. Rio dem Janeiro, 1990. 419p.

LORENZI, H. Árvores Brasileiras: Manual de Identificação e Cultivo de Plantas Nativas do Brasil, vol.01. $3^{\circ} \mathrm{Ed}$. Nova Odessa, SP.: Instituto Plantarum. 2000. 352p.

LORENZI, H. Árvores Brasileiras: Manual de Identificação e Cultivo de Plantas Nativas do Brasil, vol.02. $2^{\circ}$ Ed. Nova Odessa, SP.: Instituto Plantarum. 1998. 352p.

MAACK, R. Geografia Física do Estado do Paraná. Ed. Banco de desenvolvimento do Paraná/Universidade Federal do Paraná/Instituto de Biologia e Pesquisas Tecnológicas. Curitiba, 1968. 350p.

PADUA, S. M. Conservacion Awareness Through na Environmental Education School Program at Morro do Diabo Stat Park, S.P., Brazil, University of Florida, USA, 1997. 103p. (Dissertação de Mestrado).

REITZ, R; KLEIN, R. M; REIS, A. Projeto Madeira do Rio Grande do Sul. Editora CORAG. Porto Alegre, 1978. 525 p.

SILVA, L. H. S. Fitossociologia Arbórea da Porção Norte do Parque Estadual Mata dos Godoy, Londrina - PR. Dissertação de 
Mestrado apresentada no Setor de Ciências Biológicas da Universidade Federal do Paraná. 1990.197p.

TAKAHASHI, L. Y. Limite Aceitável de Câmbio (LAC): Manejando e Monitorando Visitantes. I Congresso Brasileiro de Unidades de Conservação. Anais. Curitiba, 1997. 445464p.

TILDEN, F. Interpreting on Heritage. The Universiti of North Carolina Press, Chapell Hill. 1957.

VASCONCELOS, J. Trilhas Interpretativas: Aliado Educação e Recreação. I Congresso Brasileiro de Unidades de Conservação. Anais. Curitiba, 1997. 465.-477.
VASCONCELOS, J. Avaliação da visitação pública e da eiciência de diferentes tipos de trilhas interpretativas no Parque Estadual Pico do Marumbi e Reserva Natural Salto Morato PR. Tese de doutorado apresentada no setor de Ciências Agrárias da Universidade Federal do Paraná. 1998.139p.

www2.ibama.gov.Br/flora/extinção.htm

ZILLER, S. R. e HATSCHBACH, G. G. (s/d). Levantamento Florístico. Projeto APA da Ilha grande, Rio Paraná - PR. 47p.

ZILLER, S. R. Avaliação Ecológica Rápida do Parque Nacional do Iguaçu. Diagnóstico Ambiental. Componente Vegetação. IBAMA/FUPEF. Curitiba, 1998. 67p. 